Historical and Philological Sciences, Dr. Solon J. Buck, director of publications of the National Archives, on "The National Archives and the Advancement of Science" ;

Engineering, Dr. Charles E. Skinner, of the Westinghouse Electric and Manufacturing Company, on "Civilisation's Debt to the Engineer";

Medical Sciences, Dr. Stanhope Bayne-Jones, of Yale University School of Medicine, on "Bacterial Poisons and Their Antidotes";

Agriculture, Dean Jacob G. Lipman, of Rutgers University, on "The Conservation of our Land Resources".

The following officers were elected for the year 1936 : President, Edwin G. Conklin, of Princeton University; Elected Council Members, Austin H. Clark, of the United States National Museum, and Arthur H. Compton, of the University of Chicago; Members of the Executive Committee, Karl T. Compton, of Massachusetts Institute of Technology, and Richard C. Tolman, of California Institute of Technology; Members of the Board of Trustees of Science Service, Burton E. Livingston, of Johns Hopkins University; Member of the Finance Com. mittee, Arthur L. Day, of the Geophysical Laboratory, Carnegie Institution of Washington; Members of the Committee on Grants, Sam F. Trelease, of Columbia University, and Joel Stebbins, of the University of Wisconsin; Secretary of the Section on Agriculture, M. F. Morgan, of Connecticut Agricultural Experiment Station.
Vice-Presidents of the Sections:

G. C. Evans, of the University of California (Mathematics) ;

George B. Pegram, of Columbia University (Physics) ;

Irving Langmuir, of the General Electric Company, Schenectady, N.Y. (Chemistry);

Frederick H. Seares, of Mt. Wilson Observatory (Astronomy) ;

George R. Mansfield, of the United States Geo. logical Survey (Geology and Geography);

Ross G. Harrison, of Yale University (Zoological Sciences) ;

J. M. Greenman, of Missouri Botanical Garden (Botanical Sciences);

Ralph Linton, of the University of Wisconsin (Anthropology) ;

Edward S. Robinson, of Yale University (Psycho. $\log y)$;

Harold G. Moulton of Brookings Institution, Washington, D.C. (Social and Economic Sciences); E. H. Wilkins, of Oberlin College (Historical and Philological Sciences);

W. E. Wickenden, of Case School of Applied Science (Engineering) ;

Joseph T. Wearn, of Western Reserve University (Medical Sciences);

P. E. Brown, of Iowa State College (Agriculture);

E. S. Evenden, of Columbia University (Education).

Henry B. Ward.

\title{
New Spectrographic Apparatus
}

$\mathrm{M}^{\mathrm{r}}$ ESSRS. ADAM HILGER, Ltd., have forwarded to us some interesting leaflets on recent developments in spectrographic apparatus. The alignment or collimation of the light source with the axis of the collimator is of great importance when any quantitative measurements of a photometric char-

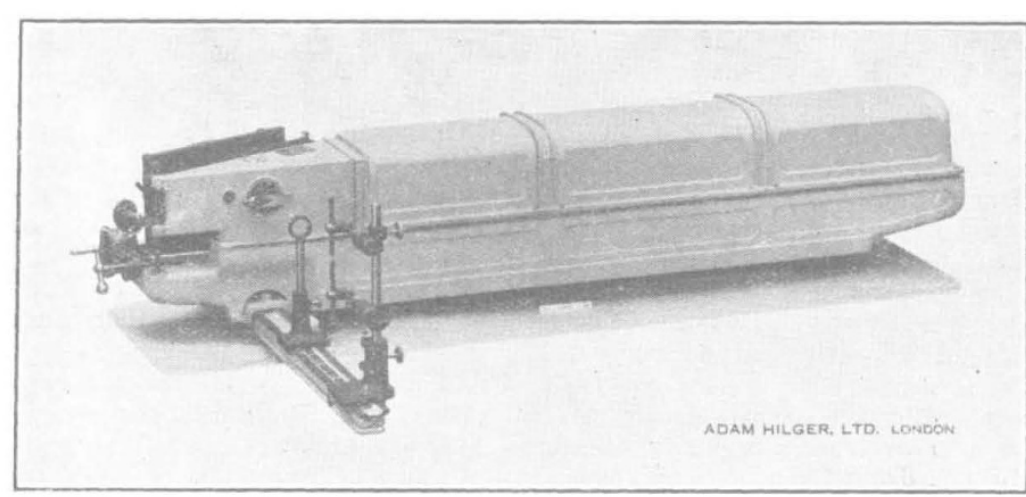

FIG. 1.

acter have to be made. Several of the spectrographs are now constructed with an accessory bar the axis of which is strictly parallel to that of the collimator. Photometer lenses and even light sources can be mounted on this 'optical bench', and the dangers of imperfect collimation are much reduced. When these instruments are used in routine testing, the time saved can be very considerable.

An entirely new departure in spectrographic apparatus is the construction of a fully automatic adjustment spectrograph. By simply rotating a handle, a glass optical train replaces one of quarte. In addition, any desired specteal range can be obtained on the plate, the focus and plate tilt being automatically set. It thus be. comes quite practical to photo. graph on the same plate an ultra-violet region with the quarte. train together with a region in the near infra-red with the glass optical parts. The enormous saving of time thus effected will be well appreciated by the many users of the prototype instrument, the Hilger E.l. It is now actually much easier to take a spectrogram with this instrument than to take an ordinary photograph with a box camera.

Concurrently with this simplification of the mechanical operations in taking a spectrum plate, there has been a steady improvement in the standard of definition of the prismsand lenses. This is strikingly shown in the enlargements of the iron triplet at $3100 \mathrm{~A}$. taken with the modern equivalents of the $E .2, E .1$, and a 3-metre quarte 
spectrograph (Publication 228/2). Readers of NATURE may be interested to compare these with the test plate photographs of their own older instruments.

Fig. 1 shows the general construction of the new automatic spectrograph $(E .478)$ fitted with an accessory bar carrying a condenser and an are source. Since a reflecting prism is mounted immediately behind the slit, the bar in this case is perpendicular to the optical axis of the instrument. It will be

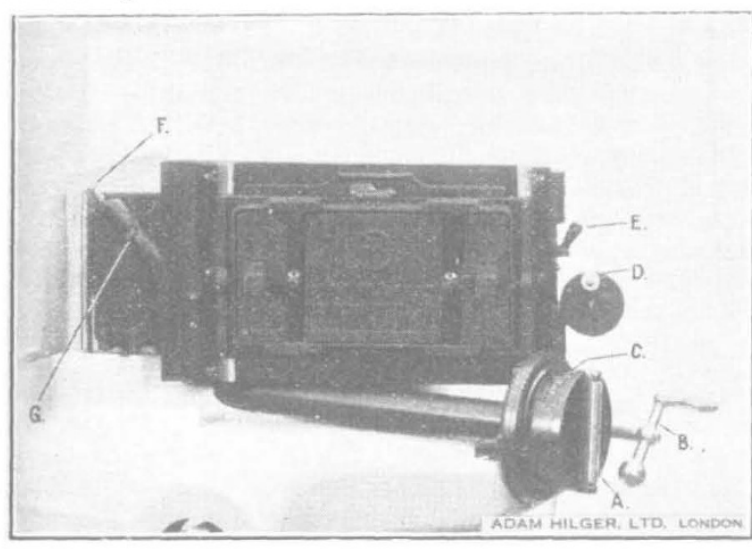

FIG. 2.

observed that the familiar wooden box is replaced by a heavy gauge, three sectioned steel covering closely fitting into a rigid steel girder. The disturbing effects of temperature variation on the air column as well as on the optical parts are considerably reduced by this method of construction. The higher standard of definition attainable with 'all metal' spectrographs must, in a great measure, be attributed to this cause.

Fig. 2 shows the plate holder and the various controls, all conveniently grouped together at this

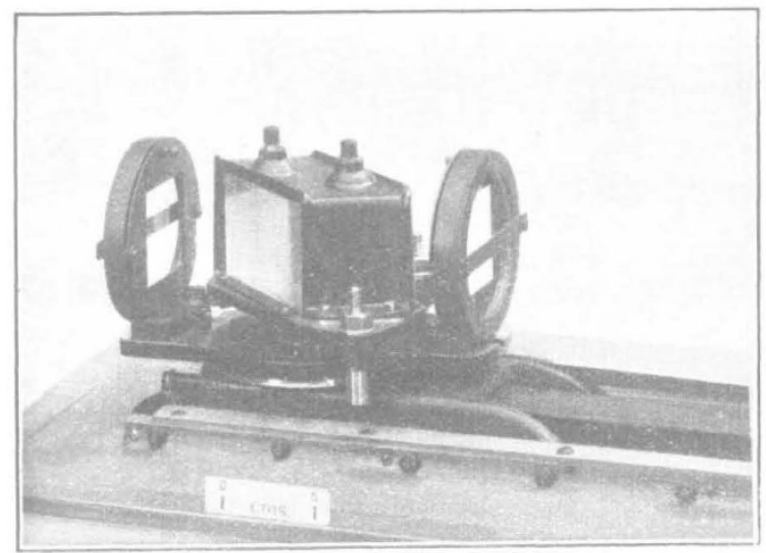

FIa. 3.

end. By turning the handle $A$ through approximately $180^{\circ}$, the optical trains are interchanged. At the same time, the long lever shown at the front of Fig. 3 comes into operation, and by means of a system of cams, the spectrograph is automatically adjusted for the wave-length range shown by the drum $C$. This range can be altered as required by rotating the handle $B$, the spectrograph adjustments being automatically performed as it is rotated. The raising and lowering of the plate holder is obtained by an improved mechanism and is controlled by the handle $D$. The lever $E$ affords means of bringing a transparent scale in contact with the photographic plate so that it is photographed on the plate together with the desired spectrum. The knurled head $F$ controls the width of the aperture available for exposure, the actual value being indicated on the scale $G$.

Fig. 3 shows the simplicity of the design for interchanging the quartz and optical trains. The prisms are mounted, back to back, in a common casing with a metallic division between them. Each system has its own lens, the one in operation being on the right of the figure. When the handle $A$ of Fig. 2 is rotated, the entire prism and lens system rotate, the second system coming into operation in exactly the correct position as determined by a definite stop.

This is the first completely automatic double train spectrograph that has been designed. In the course of time, other methods of performing the necessary operations will be evolved, but there is no doubt that the present mechanism is sufficiently sturdy to give many years of accurate service without attention

W. F. Wr.

\section{Educational Topics and Events}

Cambridar.-An election to the Sheepshanks exhibition for proficiency in astronomy will be held in the Easter term. Any member of the University under the standing of M.A., or being a research student under the standing of Ph.D., may be a candidate. The holder is required to engage in astronomical research to the satisfaction of the Council of Trinity College. Candidates are invited to send in their applications before February 14 to Prof. F. J. M. Stratton at Gonville and Caius College.

At Peterhouse, P. Ullyott has been elected fellow and director of studies in natural sciences.

LoNDON.-The title of reader in pharmacological chemistry in the University has been conferred on Dr. H. R. Ing, in respect of the post held by him at University College, and the title of reader in mechanical engineering in the University on $\mathrm{Mr}$. G. A. Wedgwood, in respect of the post held by him at Queen Mary College.

IT was announced on February 3 that Mr. Ramsay MacDonald (National Government) has been elected member of Parliament for the Scottish Combined Universities in the by-election caused by the death of Mr. Noel Skelton, Under-Secretary for Scotland.

Dr. Raymond WaLmers, president of the University of Cincinnati, in an article on "The Statistics of Registration in American Universities and Colleges, 1935" (School and Society, 42, No. 1094, December 14, 1935 , p. 801) points out that with one out of every twelve students having spare-time employment through federal appropriation, numbers in colleges and universities in the United States were $6 \cdot 6$ per cent greater than in 1934, which in turn exceeded 1933 by 5 per cent. The totals of approved institu. tions for 1935 were 588 colleges and universities, with an enrolment of $1,071,320$ students, of whom 705,989 were full-time. 